\title{
Be cautious during the interpretation of arterial blood gas analysis performed outside the intensive care unit
}

\author{
Łukasz J. Krzych ${ }^{1}$, Olga Wojnarowicz², Paweł Ignacy² and Julia Dorniak² \\ 'Department of Anaesthesiology and Intensive Care, School of Medicine in Katowice, Medical University of Silesia, Katowice, Poland; ${ }^{2}$ Students' \\ Scientific Society, Department of Anaesthesiology and Intensive Care, School of Medicine in Katowice, Medical University of Silesia, Katowice, \\ Poland
}

Introduction. Reliable results of an arterial blood gas (ABG) analysis are crucial for the implementation of appropriate diagnostics and therapy. We aimed to investigate the differences $(\Delta)$ between ABG parameters obtained from point-of-care testing (POCT) and central laboratory $(\mathrm{CL})$ measurements, taking into account the turnaround time (TAT). Materials and methods. A number of 208 paired samples were collected from 54 intensive care unit (ICU) patients. Analyses were performed using Siemens RAPIDPoint 500 Blood Gas System on the samples just after blood retrieval at the ICU and after delivery to the CL. Results. The median TAT was 56 minutes (IQR 39-74). Differences were found for all ABG parameters. Median $\Delta \mathrm{s}$ for acid-base balance were: $\Delta \mathrm{pH}=0.006$ (IQR -0.0070-0.0195), $\Delta \mathrm{BE}_{\mathrm{ef}}=-0.9$ (IQR -2.00.4 ) and $\mathrm{HCO}_{3}{ }^{-}$act $=-1.05$ (IQR $-2.25-0.35$ ). For ventilatory parameters they were: $\Delta \mathrm{pO}_{2}=-8.3 \mathrm{mmHg}$ (IQR -20.9-0.8) and $\Delta \mathrm{pCO}_{2}=-2.2 \mathrm{mmHg}$ (IQR -4.2--0.4). For electrolytes balance the differences were: $\Delta \mathrm{Na}^{+}=1.55 \mathrm{mM} / \mathrm{L}$ (IQR 0.10-2.85), $\Delta \mathrm{K}^{+}=-0.120 \mathrm{mM} / \mathrm{L}$ (IQR -0.295-0.135) and $\Delta \mathrm{Cl}^{-}=1.0 \mathrm{mM} / \mathrm{L}$ (IQR -1.0-3.0). Although the $\Delta \mathrm{s}$ might have caused misdiagnosis in 51 samples, Bland-Altman analysis revealed that only for $\mathrm{pO}_{2}$ the difference was of clinical significance (mean: $\mathbf{- 1 0 . 1} \mathrm{mmHg}, \pm 1.96 \mathrm{SD}-\mathbf{5 8 . 5}$; +38.3). There was an important correlation between TAT and $\Delta \mathrm{pH}(\mathrm{R}=0.45, p<0.01)$ with the safest time delay for proper assessment being less than 39 minutes. Conclusions. Differences between POCT and CL results in ABG analysis may be clinically important and cause misdiagnosis, especially for $\mathrm{pO}_{2}$. POCT should be advised for ABG analysis due to the impact of TAT, which seems to be the most important for the analysis of $\mathrm{pH}$.

Key words: arterial blood gas analysis, point-of-care testing, turnaround time, reliability

Received: 29 January, 2020; revised: 23 May, 2020; accepted: 28 May, 2020; available on-line: 17 September, 2020

छe-mail: I.krzych@wp.pl

Abbreviations: $A B G$, arterial blood gas; $B E$, base excess; $C L$, central laboratory; ICU, intensive care unit; IQR, interquartile range; $\mathrm{POC}(\mathrm{T})$, point-of-care (testing); TAT, turnaround time

\section{INTRODUCTION}

Laboratory blood tests help to establish the diagnosis and may influence the treatment decisions in everyday clinical practice. Their reliability is of key importance in the critical care setting as far as acid-base, electrolyte and ventilatory equilibrium are concerned. Although intensive care units (ICU) have the access to point-of-care testing (POCT), many non-ICUs still need to rely on the results from the central laboratory (CL). POCT is quick, accessible, easy-to-use, allows to reduce the possibility of pre-analytical and post-analytical errors, and significantly minimizes the turn-around-time (Nichols JH et al., 2007). Despite the improvements in sample delivery, processing and report dispatch as a result of technological advancements, the analytical turnaround time (TAT) is considered one of the crucial indicators of laboratory effectiveness and continues to be a bone of contention between the clinicians and laboratorians (Goswami B et al., 2010).

We aimed to investigate the extent of differences between major ABG parameters obtained from point-ofcare (POC) and central laboratory (CL) measurements, taking into account the time delay in blood sample analysis.

\section{MATERIALS AND METHODS}

A number of 208 paired samples were collected from 54 ICU patients hospitalized in 2018 and 2019. Blood samples were retrieved via an arterial line into two $5 \mathrm{~mL}$ heparinized probes. The paired samples were always taken by the same investigator. Measurements of $\mathrm{pH}, \mathrm{pO}_{2}$, $\mathrm{pCO}_{2}, \mathrm{HCO}_{3}^{-}$, base excess (BE), $\mathrm{Na}^{+}, \mathrm{K}^{+} \mathrm{Cl}^{-}$were performed using the Siemens RAPIDPoint 500 Blood Gas System in the ICU (as POCT) and in the CL. The time gap between the measurements (i.e. TAT) was recorded. Differences were calculated (i.e. $\Delta=$ Value $_{\mathrm{POC}}-$ Value $_{\mathrm{CI}}$ ) and POCT value was concerned as the reference one.

The project was approved by the local Ethical Committee (KNW/0022/KB1/16/I/18) and the patients gave their informed consent for participation.

Statistical analysis was performed using MedCalc for Windows v15.8 (MedCalc Software, Ostend, Belgium). Quantitative variables were presented as median and interquartile ranges (IQR, i.e. 25-75 percentile), whereas qualitative variables were depicted as relative values. All quantitative variables were tested for normal distribution using the Shapiro-Wilk test. Between-group comparisons were verified using Kruskal-Wallis test with post-hoc analysis. The correlation was assessed using Spearman's rank correlation coefficient. Bland-Altman plots were drawn to analyse the agreement between POCT and CL results. A $p$-value of $<0.05$ was considered statistically significant.

\section{RESULTS}

The study group comprised of 34 males and $20 \mathrm{fe}-$ males.

The medians of differences in parameters of acid-base balance were as follows: $\Delta \mathrm{pH}=0.0060$ (IQR -0.0070 

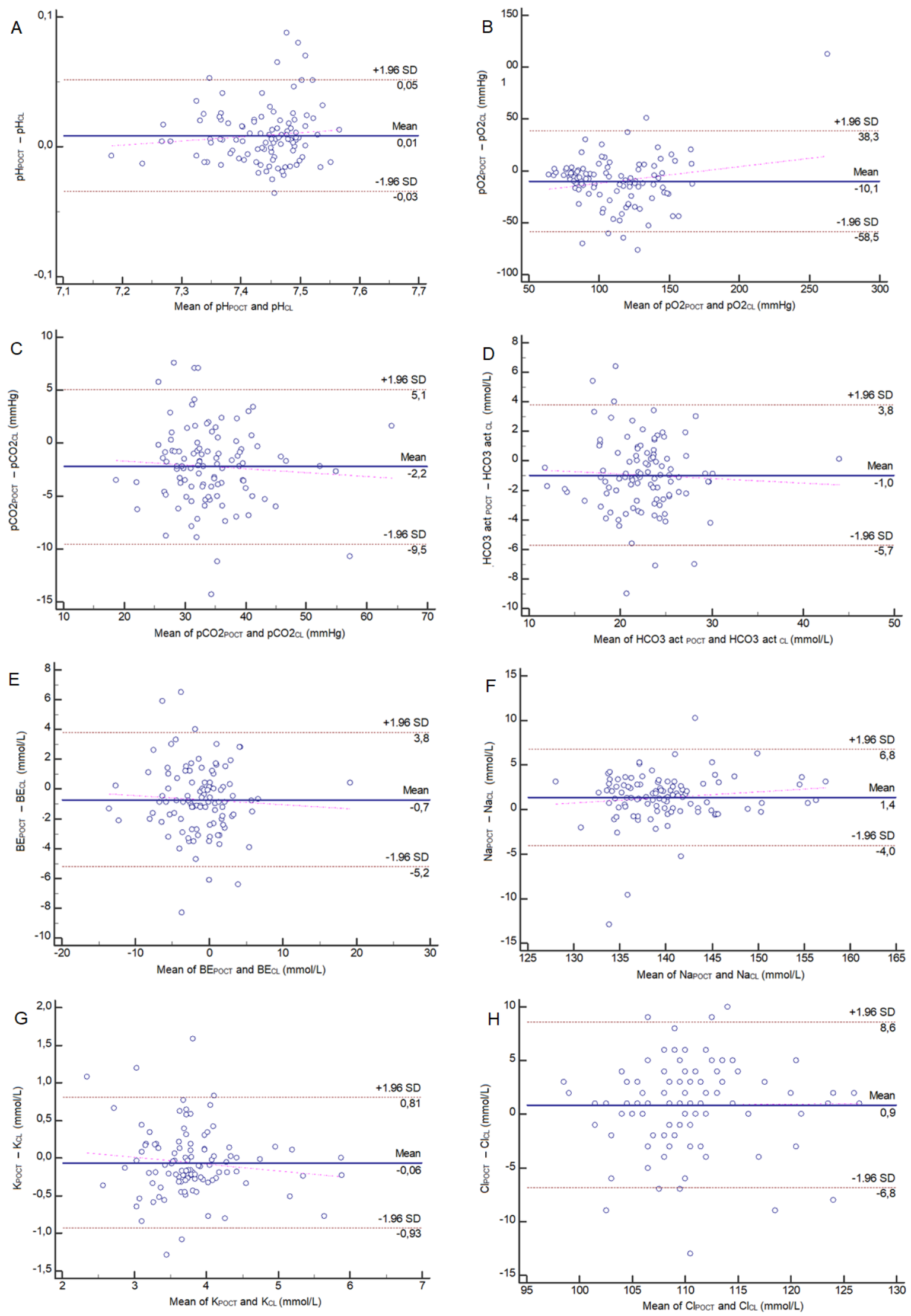

Figure 1. Bland-Altman analysis investigating differences between values obtained just after blood retrieval (POCT) and after delivery to the central laboratory $(\mathrm{CL})$

(A) $\mathrm{pH}^{\prime}$ (B) $\mathrm{pO}_{2}$ ( (C) $\mathrm{pCO}_{2}$ ( (D) $\mathrm{HCO}_{3}^{-}$; (E) $\mathrm{BE}^{2}$ (F) $\mathrm{Na}^{+}$; (G) $\mathrm{K}^{+}$; (H) $\mathrm{Cl}^{-}$ 
0.0195), $\Delta \mathrm{BE}_{\mathrm{ef}}=-0.9(\mathrm{IQR}-2.0-0.4)$ and $\mathrm{HCO}_{3}^{-}=-1.05$ (IQR -2.25-0.35). Median $\Delta \mathrm{s}$ values for ventilatory parameters were: $\Delta \mathrm{pCO}_{2}=-2.2 \mathrm{mmHg}$ (IQR -4.2--0.4) and $\Delta \mathrm{pO}_{2}=-8.3 \mathrm{mmHg}$ (IQR -20.9-0.8). As far as electrolytes were concerned, the differences were: $\Delta \mathrm{Na}^{+}=$ $1.55 \mathrm{mM} / \mathrm{L}$ (IQR 0.10-2.85), $\Delta \mathrm{K}^{+}=-0.120 \mathrm{mM} / \mathrm{L}$ (IQR $-0.295-0.135)$ and $\Delta \mathrm{Cl}^{-}=1.0 \mathrm{mM} / \mathrm{L}(\mathrm{IQR}-1.0-3.0)$. The Bland-Altman analysis revealed that only for $\mathrm{pO}_{2}$ the difference was noteworthy from the clinical and practical point of view (mean: $-10.1 \mathrm{mmHg}, \pm 1.96 \mathrm{SD}-58.5$; +38.3) (Fig. 1A-H). CL overestimated also the value of $\mathrm{pCO}_{2}, \mathrm{HCO}_{3}^{-}$act, $\mathrm{BE}_{\text {ef }}$ and $\mathrm{K}^{+}$but the variations were too small to be clinically significant.

We found a correlation only between the time delay and $\Delta \mathrm{pH}(\mathrm{R}=0.45, p<0.01)$, and $\Delta \mathrm{pCO}_{2} \quad(\mathrm{R}=0.22$, $p=0.02$ ). The median TAT was 56 minutes (IQR 39-74). Differences across the quartiles for TAT (i.e. $<39$ vs. 39$56 v$ s. 57-74 vs. $>74$ minutes) were statistically significant only for $\mathrm{pH}$ (Fig. 2A-H) with the safest time interval not exceeding 39 minutes.

The differences might have caused misdiagnosis in 51 samples for acid-base analysis, 49 for ventilatory parameters and 51 for electrolytes (Table $1 \mathrm{~A}-\mathrm{C}$ ).

\section{DISCUSSION}

In this short study we showed that the delay in $A B G$ analysis in our hospital was intolerably high, might interfere with the results and result in misdiagnosis. The difference was of significant clinical importance especially for $\mathrm{pO}_{2}(\Delta$ of $-8.3 \mathrm{mmHg}$ and mean difference of 10.1 $\mathrm{mmHg}$ in the Bland-Altman analysis). The correlation between TAT and the ABG results seems the most important in case interpretation of $\mathrm{pH}$, and TAT should not exceed 39 minutes to draw reliable therapeutic conclusions.

Although our findings are not novel in the field, this project sheds light on the proper analysis of ABG in the non-ICU setting, if POCT is inaccessible and the time delay may occur due to various local conditions (e.g. work overload in the ward, transportation problems, work overload in the CL). Different TAT may have an uncontrolled impact on $A B G$ results which results in the risk of misdiagnosis. We found that some type of misdiagnosis occurred in 51 samples. Taking into account all the analyses, the effect was found only in case of $\mathrm{pH}$ - the longer the TAT, the higher the delta. The safety margin for proper assessment was in the first TAT quartile, i.e. $<39$ minutes. In this time period, a median difference was $-0.003(95 \%$ CI $-0.14 ; 0.005)$, whereas in the second quartile it was statistically significantly higher and reached $+0.003(95 \% \mathrm{CI}-0.006 ; 0.01)(p<0.05)$. The quantity of this difference is, however, clinically unimportant and should not impact the treatment decisions. Interestingly, although not statistically significant, the difference in $\mathrm{pO}_{2}$ of $-8.3 \mathrm{mmHg}$ seems important from a practical perspective. The current guidelines recommend patient-oriented respiratory treatment with strict compliance with ABG findings. Both hypoxaemia and hyperoxaemia are harmful, so delivery of oxygen should be titrated and $\mathrm{pO}_{2}$ of $75-100 \mathrm{mmHg}$ is the goal in the vast majority of patients (de Jonge et al., 2008).

Based on our findings, we may recommend using POCT in diagnostics and treatment of ABG abnormalities via a validated bedside tool. Unjustified postponement of the analysis may cause a delay in the implementation of suitable treatment in patients with respiratory failure, shock or electrolyte disequilibrium (Szczeklik et al., 2019). The Siemens RAPIDPoint 500 Blood Gas Analyzer was found reliable in POCT and its results were found interchangeable with those obtained from the CL (where Beckman \& Coulter AU 5800 and Beckman \& Coulter UniCel DxH 800 were used) in 314 paired samples collected from 51 critically ill patients (Allardet-Servent et al., 2017).

On one hand, many investigators advise being cautious in the interpretation of electrolytes using various POC tools (Morimatsu et al., 2003; Leino et al., 2011; Budak et al., 2012; Gavala \& Myrianthefs, 2017). On the other hand, Zhang with colleagues found that the differences for electrolytes were within USCLIA-determined limits (Zhang et al., 2015) and Dashevsky et al. confirmed an excellent agreement between POC and CL for electrolytes in a cohort of almost 15000 subjects at the emergency department (Dashevsky et al., 2017). This inconsistency is difficult to explain but may arise from the analytical errors due to implementation of different tools. The strength of our study was the use of the same Siemens ABG analyzer in the ICU and in the CL. Clinicians should always be aware of the limitations of the assays they use (Uyanik et al., 2015).

There are some limitations of the study. Firstly, we focused on the selected ABG parameters. It has been revealed that the most noticeable differences between POCT and CL measurements usually concern haemoglobin, hematocrit and metabolic parameters (Allardet-Servent et al., 2017; Gavala \& Myrianthefs, 2017). Clinicians should be aware of this fact when interpreting the data if the time delay occurs. Secondly, based on our project we were unable to investigate the reason for the variations. We assumed that they were caused by the TAT. To reduce the bias, the preparation of blood samples and blood retrieval were standardized and performed by three trained investigators. But the storage of the sample and the transportation conditions may play some role. According to Srisan and coworkers (Srisan P et al., 2011), if the blood is kept in room temperature, the time delay should not exceed 20 minutes, but Mohammadhoseini and coworkers (Mohammadhoseini E et al., 2015) concluded that the results should still be reliable within 60 minutes after blood collection. Finally, we did not attempt to investigate the impact of the study group characteristics on the results. Extreme variations in ABG parameters in critically ill subjects with multiorgan failure may deliver some new interesting observations. The patients' clinical profile was of lower importance for us. However, we included only conscious patients who gave their informed consent.

\section{CONCLUSION}

We may conclude that long TAT is unacceptable and adequate urgent action is needed in the organization of work and training of employees to reduce or at least minimize this pre-analytical error. Differences between POCT and CL results in ABG analysis may be clinically important and cause misdiagnosis, especially for analysis of $\mathrm{pO}_{2}$. POCT should be advised for $\mathrm{ABG}$ analysis due to the impact of TAT, which seems to be the most important for the analysis of $\mathrm{pH}$.

\section{REFERENCES}

Allardet-Servent J, Lebsir M, Dubroca C, Fabrigoule M, Jordana S, Signouret T, Castanier M, Thomas G, Soundaravelou R, Lepidi A, Delapierre L, Penaranda G, Halfon P, Seghboyan JM (2017) Pointof-care versus central laboratory measurements of hemoglobin, he- 

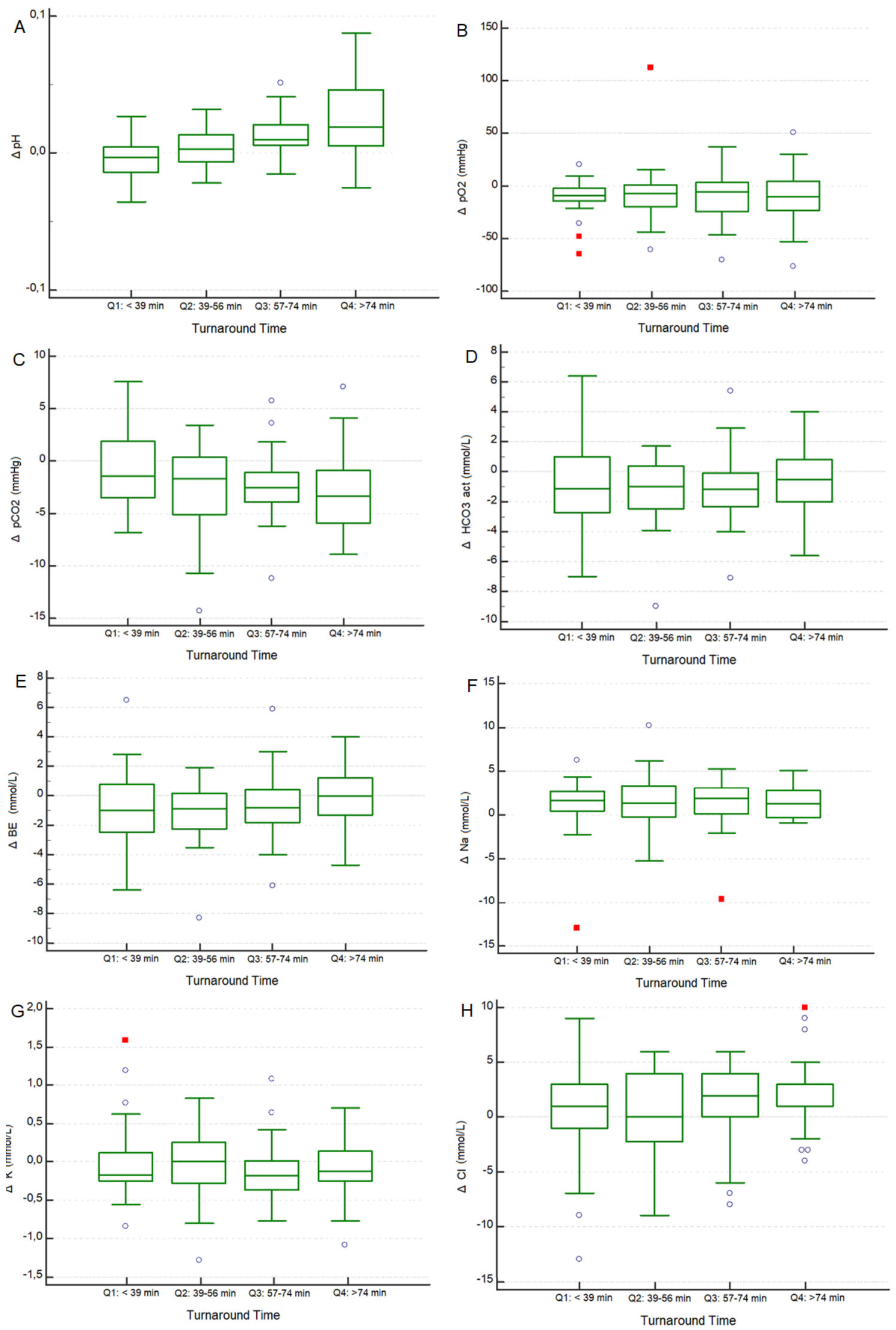

Figure 2. Differences between the values obtained just after blood retrieval (POCT) and after delivery to the central laboratory (CL) between quartiles of the turnaround time

(A) $\mathrm{pH}^{\prime}(\mathrm{B}) \mathrm{pO}_{2} ;$ (C) $\mathrm{pCO}_{2}$ ( (D) $\mathrm{HCO}_{3}{ }^{-} ;(\mathrm{E}) \mathrm{BE} ;(\mathrm{F}) \mathrm{Na}^{+} ;(\mathrm{G}) \mathrm{K}^{+} ;(\mathrm{H}) \mathrm{Cl}^{-}$ 
Table 1. Number of possible misdiagnoses due to differences between values in samples just after blood retrieval (POCT) and after delivery to the central laboratory $(\mathrm{CL})$

A. Acid-base equilibrium

\begin{tabular}{|c|c|c|c|c|c|c|c|c|c|c|}
\hline \multirow{2}{*}{$\begin{array}{l}\mathrm{CL} \\
\text { POCT }\end{array}$} & & \multicolumn{3}{|l|}{$\mathrm{pH}$} & \multicolumn{3}{|l|}{$\mathrm{BE}$} & \multicolumn{3}{|c|}{$\mathrm{HCO}_{3}{ }^{-}$act } \\
\hline & & $\downarrow$ & $\mathrm{N}$ & $\uparrow$ & $\downarrow$ & $\mathrm{N}$ & $\uparrow$ & $\downarrow$ & $\mathrm{N}$ & $\uparrow$ \\
\hline \multirow{3}{*}{$\mathrm{pH}$} & $\downarrow$ & 10 & 0 & 0 & - & - & - & - & - & \\
\hline & $\mathrm{N}$ & 4 & 29 & 7 & - & - & - & - & - & - \\
\hline & $\uparrow$ & 0 & 8 & 46 & - & - & - & - & - & - \\
\hline \multirow{3}{*}{$\mathrm{BE}$} & $\downarrow$ & - & - & - & 32 & 15 & 0 & - & - & - \\
\hline & $\mathrm{N}$ & - & - & - & 4 & 29 & 13 & - & - & - \\
\hline & $\uparrow$ & - & - & - & 0 & 2 & 9 & - & - & - \\
\hline \multirow{3}{*}{$\mathrm{HCO}_{3}{ }^{-}$act } & $\downarrow$ & - & - & - & - & - & - & 22 & 14 & 1 \\
\hline & $\mathrm{N}$ & - & - & - & - & - & - & 4 & 51 & 3 \\
\hline & $\uparrow$ & - & - & - & - & - & - & 0 & 2 & 7 \\
\hline
\end{tabular}

$\mathrm{N}$ means the norm; $\downarrow$ means below the norm; $\uparrow$ means over the norm. The norms were considered as follows: $\mathrm{pH} 7.35-7.45 ; \mathrm{BE}-2.0-3.0 \mathrm{mmol} / \mathrm{L}$; $\mathrm{HCO}_{3}-21-26 \mathrm{mmol} / \mathrm{L}$

B. Ventilatory parameters

\begin{tabular}{|c|c|c|c|c|c|c|c|}
\hline \multirow{2}{*}{$\begin{array}{l}\text { CL } \\
\text { POCT }\end{array}$} & & \multicolumn{3}{|c|}{$\mathrm{pO} 2$} & \multicolumn{3}{|c|}{$\mathrm{pCO} 2$} \\
\hline & & $\downarrow$ & $\mathrm{N}$ & $\uparrow$ & $\downarrow$ & $\mathrm{N}$ & $\uparrow$ \\
\hline \multirow{3}{*}{ pO2 } & $\downarrow$ & 4 & 1 & 2 & - & - & - \\
\hline & $\mathrm{N}$ & 0 & 28 & 13 & - & - & - \\
\hline & $\uparrow$ & 0 & 5 & 48 & - & - & - \\
\hline \multirow{3}{*}{$\mathrm{pCO} 2$} & $\downarrow$ & - & - & - & 26 & 23 & 0 \\
\hline & $\mathrm{N}$ & - & - & - & 6 & 39 & 3 \\
\hline & $\uparrow$ & - & - & - & 0 & 1 & 6 \\
\hline
\end{tabular}

$\mathrm{N}$ means the norm; $\downarrow$ means below the norm; $\uparrow$ means over the norm; The norms were considered as follows: $\mathrm{pO}_{2} 70-100 \mathrm{mmHg}$; $\mathrm{pCO}_{2} 35-46$ $\mathrm{mmHg}$

\section{Electrolytes}

\begin{tabular}{|c|c|c|c|c|c|c|c|c|c|c|}
\hline \multirow{2}{*}{$\begin{array}{l}\mathrm{CL} \\
\text { POCT }\end{array}$} & & \multicolumn{3}{|l|}{$\mathrm{Na}$} & \multicolumn{3}{|l|}{$\mathrm{K}$} & \multicolumn{3}{|l|}{$\mathrm{Cl}$} \\
\hline & & $\downarrow$ & $\mathrm{N}$ & $\uparrow$ & $\downarrow$ & $\mathrm{N}$ & $\uparrow$ & $\downarrow$ & $\mathrm{N}$ & $\uparrow$ \\
\hline \multirow[b]{3}{*}{$\frac{\pi}{2}$} & $\downarrow$ & 6 & 6 & 0 & - & - & - & - & - & - \\
\hline & $\mathrm{N}$ & 16 & 59 & 0 & - & - & - & - & - & - \\
\hline & $\uparrow$ & 0 & 5 & 12 & - & - & - & - & - & - \\
\hline \multirow[b]{3}{*}{ 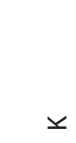 } & $\downarrow$ & - & - & - & 20 & 15 & 0 & - & - & - \\
\hline & $\mathrm{N}$ & - & - & - & 6 & 57 & 1 & - & - & - \\
\hline & $\uparrow$ & - & - & - & 0 & 0 & 5 & - & - & - \\
\hline \multirow[b]{3}{*}{$\bar{U}$} & $\downarrow$ & - & - & - & - & - & - & 0 & 0 & 0 \\
\hline & $\mathrm{N}$ & - & - & - & - & - & - & 0 & 10 & 6 \\
\hline & $\uparrow$ & - & - & - & - & - & - & 0 & 13 & 75 \\
\hline
\end{tabular}

$\mathrm{N}$ means the norm; $\downarrow$ means below the norm; $\uparrow$ means over the norm; The norms were as follows: $\mathrm{Na}^{+} 135-145 \mathrm{mmol} / \mathrm{L}_{;} \mathrm{K}^{+} 3.6-4.8 \mathrm{mmol} / \mathrm{L} ; \mathrm{Cl}^{-}$ $95-105 \mathrm{mmol} / \mathrm{L}$

matocrit, glucose, bicarbonate and electrolytes: a prospective observational study in critically Ill patients. PLoS One. 12: e0169593. https://doi.org/10.1371/journal.pone.0169593

Budak YU, Huysal K, Polat M (2012) Use of a blood gas analyzer and a laboratory autoanalyzer in routine practice to measure electrolytes in intensive care unit patients. BMC Anesthesiol. 12: 17. https://doi. org/10.1186/1471-2253-12-17

Dashevsky M, Bernstein SL, Barsky CL, Taylor RA (2017) Agreement between serum assays performed in ED point-of-care and hospital central laboratories. West J. Emerg. Med. 18: 403-409. https://doi. $\mathrm{org} / 10.5811 /$ westjem.2017.1.30532 de Jonge E, Peelen L, Keijzers PJ, Joore H, de Lange D, van der Voort PH, Bosman RJ, de Waal RA, Wesselink R, de Keizer NF (2008) Association between administered oxygen, arterial partial oxygen pressure and mortality in mechanically ventilated intensive care unit patients. Crit Care. 12: R156. https://doi.org/10.1186/cc7150

Gavala A, Myrianthefs P (2017) Comparison of point-of-care versus central laboratory measurement of hematocrit, hemoglobin, and electrolyte concentrations. Heart Lung. 46: 246-250. https://doi. org/10.1016/j.hrtlng.2017.04.003

Goswami B, Singh B, Chawla R, Gupta VK, Mallika V (2010) Turn Around Time (TAT) as a Benchmark of Laboratory Performance. 
Indian J. Clin. Biochem. 25: 376-379. https://doi.org/10.1007/s12291010-0056-4

Leino A, Kurvinen K (2011) Interchangeability of blood gas, electrolyte and metabolite results measured with point-of-care, blood gas and core laboratory analyzers. Clin. Chem. Lab. Med. 49: 1187-1191. https://doi.org/10.1515/CCLM.2011.185

Mohammadhoseini E, Safavi E, Seifi S, Seifirad S, Firoozbakhsh S, Peiman S (2015) Effect of sample storage temperature and time delay on blood gases, bicarbonate and $\mathrm{pH}$ in human arterial blood samples. Iran. Red. Crescent. Med. J. 17: e13577. https://doi.org/10.5812/ ircmj.13577

Morimatsu H, Rocktäschel J, Bellomo R, Uchino S, Goldsmith D, Gutteridge G (2003) Comparison of point-of-care versus central laboratory measurement of electrolyte concentrations on calculations of the anion gap and the strong ion difference. Anesthesiology 98: 10771084. https://doi.org/10.1097/00000542-200305000-00009

Nichols JH, Christenson RH, Clarke W, Gronowski A, HammettStabler CA, Jacobs E, Kazmierczak S, Lewandrowski K, Price C, Sacks DB, Sautter RL, Shipp G, Sokoll L, Watson ID, Winter W, Zucker ML; National Academy of Clinical Biochemistry (2007) Executive summary. The National Academy of Clinical Biochemistry
Laboratory Medicine Practice Guideline. Evidence-based practice for point-of-care testing. Clin. Chim. Acta. 379: 14-28. https://doi. org $10.1016 /$ j.cca.2006.12.025

Srisan P, Udomsri T, Jetanachai P, Lochindarat S, Kanjanapattanakul W (2011) Effects of temperature and time delay on arterial blood gas and electrolyte measurements. J. Med. Assoc. Thai. 94: 9-14

Szczeklik W, Fronczek J, Górka J, Banaszewska A, Gałkin P, Goździk W, Kudliński B, Kutaj-Wasikowska H, Polok K, Włudarczyk A, Nowina-Konopka M, Wołk-Popielska A, Jaeschke R (2019) Introduction of rapid response teams in Poland. Anaesthesiol. Intensive Ther. 51: 178-185. https://doi.org/10.5114/ait.2019.87647

Uyanik M, Sertoglu E, Kayadibi H, Tapan S, Serdar M, Bilgi C, Kurt I (2015) Comparison of blood gas, electrolyte and metabolite results measured with two different blood gas analyzers and a core laboratory analyzer. Scand. J. Clin. Lab. Invest. 75: 97-105. https://doi.org/ 10.3109/00365513.2014.981854

Zhang JB, Lin J, Zhao XD (2015) Analysis of bias in measurements of potassium, sodium and hemoglobin by an emergency departmentbased blood gas analyzer relative to hospital laboratory autoanalyzer results. PLoS One. 10: e0122383. https://doi.org/10.1371/journal. pone. 0122383 